Journal of Patient-Centered

\title{
Application of the Breastfeeding Personal Efficacy Beliefs Inventory and Acknowledgment of Barriers for Improving Breastfeeding Initiation Rates in an Urban Population
}

\author{
Diwata Bose \\ Callie Cox Bauer \\ Kiley A. Bernhard \\ Dennis J. Baumgardner
}

Follow this and additional works at: https://aah.org/jpcrr

Part of the Maternal and Child Health Commons, Public Health Education and Promotion Commons, and the Women's Health Commons

\section{Recommended Citation}

Bose D, Bauer C, Bernhard KA, Baumgardner DJ. Application of the breastfeeding personal efficacy beliefs inventory and acknowledgment of barriers for improving breastfeeding initiation rates in an urban population. J Patient Cent Res Rev. 2014;1:77-84. doi: 10.17294/2330-0698.1016

Published quarterly by Midwest-based health system Advocate Aurora Health and indexed in PubMed Central, the Journal of Patient-Centered Research and Reviews (JPCRR) is an open access, peer-reviewed medical journal focused on disseminating scholarly works devoted to improving patient-centered care practices, health outcomes, and the patient experience. 


\title{
Application of the Breastfeeding Personal Efficacy Beliefs Inventory and Acknowledgment of Barriers for Improving Breastfeeding Initiation Rates in an Urban Population
}

Diwata Bose, MD, ${ }^{1}$ Callie Cox Bauer, DO, ${ }^{2,3}$ Kiley A. Bernhard, MPH, ${ }^{3,4}$ Dennis J. Baumgardner, MD $^{3,4,5}$

\author{
${ }^{1}$ Department of Obstetrics and Gynecology, University of Wisconsin School of Medicine and Public Health, Aurora UW \\ Medical Group, Milwaukee, WI \\ ${ }^{2}$ Department of Obstetrics and Gynecology, Aurora Medical Education, Milwaukee, WI \\ ${ }^{3}$ Aurora Health Care, Milwaukee, WI \\ ${ }^{4}$ Center for Urban Population Health, Milwaukee, WI \\ ${ }^{5}$ Department of Family Medicine, University of Wisconsin School of Medicine and Public Health, Aurora UW Medical \\ Group, Milwaukee, WI
}

\begin{abstract}
Introduction: Breastfeeding (BF) is recognized as the preferred method of infant nutrition by American Academy of Pediatricians, American College of Obstetricians and Gynecologists, and the World Health Organization. Despite the benefits of BF, in 1998 only $69 \%$ of new mothers in the United States initiated BF and $29 \%$ continued to breastfeed at 6 months.
\end{abstract}

Objective: To assess perceived breastfeeding confidence (BFC) and determine barriers in regards to $\mathrm{BF}$ in an urban population.

Methods: The Breastfeeding Personal Efficacy Beliefs Inventory (BPEBI) was used to determine perceived BFC. The survey was distributed to 271 women during prenatal appointments at an urban Milwaukee medical center. BF initiation rate at discharge was determined by records review. A principal component factor analysis with varimax rotation was used to examine the structure of the BPEBI in this population.

Results: Survey response rate was $89 \%$. Overall BFC was $74 \%$. $\mathrm{BF}$ initiation rate at discharge was $62 \%$, exclusively $\mathrm{BF}(\mathrm{EBF})$ at discharge (no bottle-feeding) was 55\%. In multivariate models, EBF decreased with black race $(\mathrm{p}=0.02)$ and with residence in the low socioeconomic status zip codes of the central city of Milwaukee $(\mathrm{p}=0.01)$. BFC increased with prior exposure to $B F(p=0.03)$, EBF $(p=0.03)$ and length of $B F(p=0.02)$. Factor analysis identified two constructs: $\mathrm{BFC}$ increased with prior exposure to $\mathrm{BF}(\mathrm{p}=0.006)$ and $\mathrm{EBF}(\mathrm{p}=0.001)$ within the motivation construct, and BFC increased with $\mathrm{EBF}(\mathrm{p}=0.000)$ within the technique/environment construct.

Correspondence: Kiley A. Bernhard, MPH

1020 N. 12th Street, Suite 4180, Milwaukee, WI 53233,

Phone: 414-219-5594; Fax: 414-219-6563,

Email: kbernhard7@gmail.com
Conclusions: The main barriers to increased BFC were lack of prior exposure to $\mathrm{BF}$ and nonexclusive breastfeeding practices. $\mathrm{BF}$ initiation rate at discharge was low compared to self-reported level of confidence. EBF decreased with black race and with closer proximity to the central city of Milwaukee. (J Patient-Centered Res Rev. 2014;1:77-84.)

\section{Keywords}

breastfeeding, lactation, infant food, maternal behavior, self-concept

\section{Introduction}

Breastfeeding (BF) is recognized as the preferred method of infant nutrition. The American Academy of Pediatricians recently reaffirmed its recommendation of exclusively breastfeeding (EBF) for 6 months, followed by continuation of breastfeeding until 1 year of age as complementary foods are introduced. ${ }^{1}$ The World Health Organization ${ }^{2}$ and the American College of Obstetricians and Gynecologists ${ }^{3-6}$ concur with the recommendation. Breast milk provides immunity, is nutritionally balanced, easily digested and promotes healthy growth in infants. ${ }^{2} \mathrm{BF}$ is associated with lower rates of disease in the newborn including a decrease in sudden infant death syndrome; decreased respiratory, gastrointestinal and ear infections; and a reduction in children with allergies and asthma. ${ }^{7}$ Proven benefits to the mother also have been noted, with a decrease in breast and ovarian cancer. ${ }^{7}$

Despite the benefits of BF, in 1998 only 69\% of Americans initiated BF and 29\% continued to breastfeed at 6 months. Therefore, BF was made a goal of Healthy People 2020, with an ideal initiation rate of $81.9 \%, 6$-month rate of $60.6 \%$ and 1-year rate of $34.1 \% .{ }^{8}$ Overall $\mathrm{BF}$ rates continue to rise in the United States. In 2012 the Centers for Disease Control and Prevention estimated the national rate of initiation of $\mathrm{BF}$ 
to be $76.9 \%$ and the rate of BF to be $47.2 \%$ and $25.5 \%$ at 6 and 12 months, respectively. ${ }^{9}$ The rates reported for Wisconsin are similar, with BF initiation of $81.3 \%$ and continuation of $48.7 \%$ at 6 months and $21.9 \%$ at 12 months. In contrast, the urban population of Milwaukee, Wisconsin, has an initiation rate of $62.8 \%, \mathrm{BF}$ rate at 6 months of $22.2 \%$, and at 12 months of $10.4 \% .{ }^{10}$ These rates are significantly lower than the overall state rates and are far from the Healthy People 2020 goals.

Interventions to increase BF rates, particularly initiation rates, are needed in populations with inherently low rates of $\mathrm{BF}$ initiation. Evaluation and understanding of such population's self-efficacy about BF is important to guide meaningful community interventions to increase initiation and duration of BF. The theory of self-efficacy has as its premise the belief in one's own capabilities to accomplish a task to reach a given outcome. Using personal efficacy beliefs, one can measure individuals' confidence levels in managing their introspection, response and environment to produce the desired effects, which helps predict that individual's behavior. This then serves as a guide to the development of interventions to modify the self-efficacy beliefs. ${ }^{11,12}$

The Breastfeeding Personal Efficacy Beliefs Inventory (BPEBI) addresses the perceived self-efficacy of women prior to initiation of $\mathrm{BF}$ and is a logical choice to explore these issues. This survey was chosen as it had been previously validated to find confidence levels and barriers to breastfeeding initiation. Survey validation occurred in a predominantly white, younger aged, university student population. ${ }^{13}$

The primary objective of this project was to assess perceived breastfeeding confidence (BFC) and determine barriers related to $\mathrm{BF}$ at an urban hospital with a low BF initiation rate. In addition, we sought to determine the structure of the BPEBI as an instrument in this population. This information will aid in developing the appropriate interventions for improving BF initiation rates and, ultimately, increasing the percentage of women who practice EBF for 6 months.

\section{Methods}

Data collection was attained through a previously validated survey: the BPEBI. ${ }^{13}$ The BPEBI survey was distributed to 271 pregnant women attending prenatal appointments at an academic clinic in downtown Milwaukee. The clinic serves primarily low-income, inner-city women who participate in a state-administered insurance plan that covers pregnantwomen and their families with income up to $300 \%$ of the federal poverty level. There were approximately 4,200 nonunique clinic patient visits in 2012, of which $60 \%(2,533)$ were black, $75 \%(3,169)$ were between the ages of $20-44$, and $55 \%$ were on Medicaid.

The survey was distributed at clinic visits to all women who were currently pregnant. Over a period of 2 months, all eligible patients were approached and recruited to voluntarily participate by the project coordinator. In the examination room, directions were explained by the project coordinator to willing patients, and one example question was practiced with the patient prior to allowing her to confidentially complete the survey. The survey was then placed into an envelope and returned anonymously to the staff at the end of the appointment.

This survey was used to measure women's confidence in all aspects of breastfeeding. The survey included 24 questions using a visual analogue scale measurement instrument, followed by 12 demographic questions. The visual analogue scale is used to measure attitudes that are otherwise difficult to measure. The instrument allows participants to mark anywhere along a horizontal line to represent their level of confidence from 0 (cannot do) to 50\% (might do) to $100 \%$ (certain can do), with $0 \%$ being no confidence and $100 \%$ being complete confidence. The point at which the line was marked was measured via ruler and converted to a percentage.

A principal component factor analysis with varimax rotation was used to examine the structure of the BPEBI. The goal of principal component factor analysis is to reflect the magnitude of the stable common and specific variance. Reliabilities are used when the objective is to study the nature of the theoretical factors that best account for the stable variance of the variables. ${ }^{14}$ Varimax rotation is considered uncorrelated and is used to simplify the structure and interpretation of the eigenvectors; it focuses on creating as many values in each column of the factor-loading coefficients table to be as close to zero as possible. ${ }^{14}$ The criterion for the determination of the number of factors was an eigenvalue of greater than 1 and a loading factor of 0.3. Four items did not meet the factorloading criteria: "breastfeeding my baby for one year," "getting the information I need about BF," "eating mostly as I please while BF," and "taking most medications I need."

An inventory score was determined for each of the 24 items on the survey by calculating the mean score. An overall inventory score was calculated by taking the mean score of the individual inventory scores. Additionally, an inventory score was calculated separately for the two constructs that ultimately resulted from the factor analysis, based on the items that made up the constructs. 
Quantitative data were analyzed utilizing Minitab ${ }^{\circledR}$ software (Minitab Inc., State College, PA). Demographic data were summarized using descriptive statistics. Categorical data were analyzed using chi-square tests (with Yates correction for $2 \times 2$ tables). Groups of score variables were compared with the Mann-Whitney test. Univariate regression was used to determine association of predictor variables with individual inventory score, and multivariate models were constructed with the significant variables. Statistical significance was determined at $\mathrm{P}<0.05$, with a $95 \%$ confidence interval.

Aggregate BF initiation rate at discharge, marital status, insurance provider, and permanent address by zip code were determined by medical chart review from a list of all patients approached to participate in the project. The project was submitted to the local Institution Review Board and deemed not to be human subject research.

\section{Results}

Of 271 patients asked to participate, 240 returned the survey for a response rate of $89 \%$. The mean age was $25.3 \pm 5.7$ years, and median age was 24 years (range: 26 years). The project population was $58 \%(\mathrm{n}=158)$ black, $83 \%(\mathrm{n}=226)$ single/ not married, $83 \%(n=225)$ on Medicaid, and $67 \%$ from low socioeconomic status (SES) zip codes of the central city of Milwaukee. ${ }^{15}$ Based on demographic information from this clinic, this project population was a representative sample of the clinic population.

The project population's level of education varied, with $64 \%(\mathrm{n}=121)$ of individuals with a high school diploma/ GED, $13 \%(n=25)$ with less than a high school education, $13 \%(n=24)$ with an associate's degree/junior college education, $6 \%(n=12)$ with a bachelor's degree, and $3 \%(n=6)$ with a graduate degree. Nearly half of spouses/partners had occupations in the governmental job categories of Operative $(20 \%, n=28)$, Service Worker $(15 \%, n=22)$ or Craft Worker $(12 \%, n=17) ; 14 \%(n=20)$ of the patients reported that their spouse or partner was unemployed. Table 1 provides demographic description of the project population.

The project population consisted of $33 \% \quad(n=77)$ of patients reporting first pregnancy; in the 67\% $(n=156)$ who reported this was not their first pregnancy, the median number of children was one. In women who reported a prior pregnancy, $39 \%(\mathrm{n}=91)$ reported $\mathrm{BF}$ in the past, for an average length of 5.5 months $( \pm 6.16)$. In women who reported $\mathrm{BF}$ in the past, $52 \%(\mathrm{n}=47)$ were very satisfied, $37 \%(n=34)$ were somewhat satisfied and $11 \%$ $(n=10)$ were a little satisfied. Among these same women,
Table 1. Population demographics

\begin{tabular}{|c|c|c|}
\hline Variable & Frequency & Percentage \\
\hline \multicolumn{3}{|l|}{ Race $(n=271)$} \\
\hline Unknown & 15 & 5.5 \\
\hline White & 45 & 16.6 \\
\hline Black & 158 & 58.3 \\
\hline Hispanic & 38 & 14.0 \\
\hline Asian & 9 & 3.3 \\
\hline Mixed/Other & 6 & 2.2 \\
\hline \multicolumn{3}{|l|}{ Marital status $(n=271)$} \\
\hline Unknown/not applicable & 1 & 0.4 \\
\hline Single/not married & 226 & 83.4 \\
\hline Married & 39 & 14.4 \\
\hline Divorced & 4 & 1.5 \\
\hline Widowed & 1 & 0.4 \\
\hline \multicolumn{3}{|l|}{ Insurance $(n=271)$} \\
\hline None & 32 & 11.8 \\
\hline Medicaid & 225 & 83.0 \\
\hline Commercial & 14 & 5.2 \\
\hline \multicolumn{3}{|l|}{ Education level $(n=188)$} \\
\hline Less than high school & 25 & 13.3 \\
\hline High school diploma/GED & 121 & 64.4 \\
\hline Associate's degree/junior college & 24 & 12.8 \\
\hline Bachelor's degree & 12 & 6.4 \\
\hline Graduate degree & 6 & 3.2 \\
\hline \multicolumn{3}{|l|}{ Occupation $(n=143)$} \\
\hline Unemployed & 20 & 14.0 \\
\hline Professional & 10 & 7.0 \\
\hline Official/manager & 5 & 3.5 \\
\hline Technician & 2 & 1.4 \\
\hline Sales worker & 11 & 7.7 \\
\hline Administrative support & 6 & 4.2 \\
\hline Craft worker & 17 & 11.9 \\
\hline Operative & 28 & 19.6 \\
\hline Laborer/helper & 11 & 7.7 \\
\hline Service worker & 22 & 15.4 \\
\hline Student & 11 & 7.7 \\
\hline
\end{tabular}

$46 \%(n=42)$ provided all, $23 \%(n=21)$ provided most, $17 \%$ $(\mathrm{n}=15)$ provided some, $11 \%(\mathrm{n}=10)$ provided a little, and two provided none of their baby's diet during the early weeks of BF. In the overall project population, $58 \%(n=137)$ of women reported they had a sister or close friend who had breastfed in the past, of which $57 \%(n=78)$ reported that she was very satisfied with BF. Table 2 provides a summary of the participants' BF and pregnancy experience.

$\mathrm{BFC}$ was based on the calculated overall inventory score. The overall inventory score was 74.8. EBF (no bottle-feeding) initiation rate at hospital discharge was $50 \%$; the overall $\mathrm{BF}$ initiation rate (meaning the mother put the baby to the breast at least once) was $56 \%$, and $34 \%$ of mothers were only bottle-feeding at discharge, based on records review.

Two factors resulted from factor analysis based on the predetermined criteria. Varimax rotation was used because items were believed to be heterogeneous. A loading factor 
Table 2. Summary of participants' breastfeeding (BF) and pregnancy experience

\begin{tabular}{|c|c|c|}
\hline Variable & Frequency & Percentage \\
\hline $\begin{array}{l}\text { Exclusively BF at hospital } \\
\text { discharge }(n=271)\end{array}$ & 136 & 50.2 \\
\hline Bottle-feeding at discharge (no BF) & 92 & 33.9 \\
\hline BF and bottle-feeding at discharge & 17 & 6.3 \\
\hline BF initiation unknown & 26 & 9.6 \\
\hline $\begin{array}{l}\text { Overall BF at hospital discharge } \\
\text { (BF and bottle-feeding) }\end{array}$ & 153 & 56.5 \\
\hline \multicolumn{3}{|l|}{ Breastfed as baby $(n=233)$} \\
\hline No & 99 & 42.5 \\
\hline Yes & 75 & 32.2 \\
\hline Do not know & 59 & 25.3 \\
\hline \multicolumn{3}{|l|}{ First pregnancy $(\mathrm{n}=233)$} \\
\hline No & 156 & 67.0 \\
\hline Yes & 77 & 33.1 \\
\hline \multicolumn{3}{|l|}{$\begin{array}{l}\text { Sister/close friend breastfed } \\
(n=235)\end{array}$} \\
\hline No & 97 & 41.3 \\
\hline Yes & 137 & 58.3 \\
\hline \multicolumn{3}{|l|}{$\begin{array}{l}\text { Number of children }(n=234, \\
\text { mean }=1.53, S D=1.65, \text { median }=1)\end{array}$} \\
\hline None & 79 & 33.8 \\
\hline One & 62 & 26.5 \\
\hline Two & 33 & 14.1 \\
\hline Three & 32 & 13.7 \\
\hline Four & 19 & 8.1 \\
\hline Five & 3 & 1.3 \\
\hline Six & 3 & 1.3 \\
\hline Seven & 1 & 0.4 \\
\hline Nine & 2 & 0.9 \\
\hline \multicolumn{3}{|l|}{$\begin{array}{l}\text { Sister/close friend satisfaction } \\
(n=137)\end{array}$} \\
\hline Little & 7 & 5.1 \\
\hline Some & 46 & 33.6 \\
\hline A lot & 78 & 56.9 \\
\hline \multicolumn{3}{|l|}{$\begin{array}{l}\text { Prior } \mathrm{BF}^{* *}(\mathrm{n}=234, \text { mean } \\
\text { length }=5.5, \mathrm{SD}=6.16 \text {, } \\
\text { median }=3.5)^{*}\end{array}$} \\
\hline No & 142 & 60.7 \\
\hline Yes & 91 & 38.9 \\
\hline \multicolumn{3}{|l|}{ Diet supplied $(n=91)$} \\
\hline None & 2 & 2.2 \\
\hline Little & 10 & 11.0 \\
\hline Some & 15 & 16.5 \\
\hline Most & 21 & 23.1 \\
\hline All & 42 & 46.2 \\
\hline \multicolumn{3}{|l|}{ Satisfaction with prior BF $(n=91)$} \\
\hline Little & 10 & 11.0 \\
\hline Some & 34 & 37.4 \\
\hline A lot & 47 & 51.6 \\
\hline
\end{tabular}

$S D$, standard deviation.

*Mean and median length of breastfeeding was calculated from previous pregnancies in number of months.

${ }^{* *}$ Timing of prior exposure was not known. of 0.3 was used to determine the two-factor solution. If each factor had a loading factor $>0.3$, the higher value was used to determine which construct the item belonged. Factor 1 measured women's BF confidence about the beneficial aspects of BF (all items had a factor loading score $>0.3$ ) and was designated Confidence to Manage Motivation. This construct included survey items such as "improves my baby's intelligence by BF," "make safe milk," and "have a pleasant experience while BF." Factor 2 reflected confidence about technical and environmental aspects (all items had a factor loading score $>0.3$ ). This was designated Confidence to Manage Technique and Environment. This construct included items such as "provide all food," "breast size doesn't matter," and "BF while immediate family present." The twofactor solution explained $46 \%$ of variance. Before testing, five factors had been hypothesized based on a previous study conducted by Cleveland et al.; ${ }^{13}$ however, no items met the factor-loading criteria in the other factors. Table 3 provides the factor loadings for the two factors. Table 4 provides the factor loadings for all 24 items.

Inventory scores were calculated for the Motivation Construct and the Technique and Environment Construct, and were 81 and 70, respectively. The items with the highest individual inventory scores show that patients were confident in their ability to get information about BF (92), BF during the nighttime (87.2) and BF right after birth (87). The items with the lowest individual inventory score demonstrated patients lacked the confidence to "take most medications I need while BF" (44.1), "eat mostly as I please" (54.6), and "ease my return to work by BF" (60.7). Table 5 provides a summary of individual inventory scores for each of the 24 items on the survey.

Univariate regression was performed to measure the effect of age, prior exposure to BF, first pregnancy, EBF during the early weeks (100\% of diet was supplied) and length of BF compared to the individual inventory score (BFC). All variables were statistically significant, with P-values of $0.009,0.001,0.03,0.01$ and 0.04 , respectively. Overall, when taken together, the variables explained $19 \%$ of the variance in BFC. Multivariate models were constructed from these variables and revealed that $\mathrm{BFC}$ increased with prior exposure to $\mathrm{BF}(\mathrm{P}=0.03), \mathrm{EBF}(\mathrm{P}=0.03)$ and length of $\mathrm{BF}(\mathrm{P}=0.02)$.

When the individual inventory score was analyzed separately by construct, there was significant difference in the Motivation Construct, noting statistical significance in patients with a history of prior exposure to $\mathrm{BF}(\mathrm{P}<0.001)$ and EBF during the early weeks $(\mathrm{P}=0.001)$. These two variables 
Table 3. Factor analysis of BPEBI by construct

\begin{tabular}{|c|c|c|}
\hline Confidence to: & Factor 1 & Factor 2 \\
\hline \multicolumn{3}{|l|}{ Manage motivation } \\
\hline $\begin{array}{l}\text { Have a pleasant time while } \\
\text { breastfeeding }\end{array}$ & $\underline{0.61}$ & 0.27 \\
\hline $\begin{array}{l}\text { Improves my baby's intelligence } \\
\text { by breastfeeding }\end{array}$ & $\underline{0.68}$ & ---- \\
\hline $\begin{array}{l}\text { Ease my return to work by } \\
\text { breastfeeding }\end{array}$ & $\underline{0.30}$ & 0.19 \\
\hline $\begin{array}{l}\text { Improves baby's health by } \\
\text { breastfeeding }\end{array}$ & $\underline{0.69}$ & 0.10 \\
\hline Make safe milk for my baby & $\underline{0.59}$ & 0.13 \\
\hline Save money by breastfeeding & $\underline{0.72}$ & 0.22 \\
\hline $\begin{array}{l}\text { Bond easily with my baby by } \\
\text { breastfeeding }\end{array}$ & $\underline{0.59}$ & 0.36 \\
\hline $\begin{array}{l}\text { Expect support from spouse/ } \\
\text { partner }\end{array}$ & $\underline{0.54}$ & 0.18 \\
\hline $\begin{array}{l}\text { Get help with my baby by } \\
\text { breastfeeding }\end{array}$ & $\underline{0.33}$ & 0.17 \\
\hline $\begin{array}{l}\text { Breastfeed my baby during the } \\
\text { nighttime }\end{array}$ & $\underline{0.65}$ & 0.41 \\
\hline $\begin{array}{l}\text { Breastfeed my baby right after birth } \\
\text { Manage technique and } \\
\text { environments }\end{array}$ & $\underline{0.62}$ & 0.32 \\
\hline $\begin{array}{l}\text { Breastfeed with my immediate } \\
\text { family present }\end{array}$ & 0.22 & $\underline{0.73}$ \\
\hline Breastfeed at the mall & 0.14 & $\underline{0.60}$ \\
\hline $\begin{array}{l}\text { Pump at work to save milk for my } \\
\text { baby }\end{array}$ & 0.05 & $\underline{0.53}$ \\
\hline $\begin{array}{l}\text { Doing most activities with } \\
\text { breastfeeding }\end{array}$ & 0.23 & $\underline{0.32}$ \\
\hline $\begin{array}{l}\text { Breastfeed no matter the size of } \\
\text { my breasts }\end{array}$ & 0.26 & $\underline{0.57}$ \\
\hline $\begin{array}{l}\text { Learn to get my baby on and off } \\
\text { the breast }\end{array}$ & 0.38 & $\underline{0.39}$ \\
\hline $\begin{array}{l}\text { Breastfeed my baby for three } \\
\text { months }\end{array}$ & 0.45 & $\underline{0.57}$ \\
\hline Breastfeed my baby for six months & 0.26 & $\underline{0.37}$ \\
\hline Provide all food for several months & 0.35 & $\underline{0.56}$ \\
\hline Eigenvalues & 9.2 & 1.8 \\
\hline$\%$ of variance & 38.3 & 7.7 \\
\hline & & Total $=46 \%$ \\
\hline
\end{tabular}

BPEBI, Breastfeeding Personal Efficacy Beliefs Inventory.

Factor loading $>0.3$; eigenvalue $>1$.

Note: The item-loading statistic that is underlined indicates the subscale to which each item was assigned.

accounted for $10 \%$ of variance in BFC within the Motivation Construct. Within the Technique and Environment Construct, age ( $\mathrm{P}=0.008)$, prior exposure to $\mathrm{BF}(\mathrm{P}=0.006)$, first pregnancy $(\mathrm{P}=0.04)$ and $\mathrm{EBF}$ during the early weeks $(\mathrm{P}<0.001)$ were all statistically significant. These four variables accounted for $18 \%$ of the variance (11\% from the
Table 4. Factor loadings for all 24 items on the BPEBI

\begin{tabular}{|c|c|c|}
\hline Item Name & Motivation & $\begin{array}{c}\text { Techniquel } \\
\text { Environment }\end{array}$ \\
\hline $\begin{array}{l}\text { Improves my baby's intelligence } \\
\text { by breastfeeding }\end{array}$ & $\underline{0.679}$ & ---- \\
\hline During the nighttime & $\underline{0.646}$ & 0.405 \\
\hline Bond with baby & $\underline{0.591}$ & 0.358 \\
\hline Right after birth & $\underline{0.623}$ & 0.320 \\
\hline Have a pleasant experience & $\underline{0.605}$ & 0.267 \\
\hline Save money & $\underline{0.720}$ & 0.216 \\
\hline Ease return to work & $\underline{0.304}$ & 0.191 \\
\hline $\begin{array}{l}\text { Expect support from spouse/ } \\
\text { partner }\end{array}$ & $\underline{0.540}$ & 0.184 \\
\hline Get help with baby & $\underline{0.330}$ & 0.169 \\
\hline Make safe milk & $\underline{0.594}$ & 0.128 \\
\hline Increase baby's health & $\underline{0.693}$ & 0.095 \\
\hline Immediate family present & 0.219 & $\underline{0.733}$ \\
\hline At the mall & 0.135 & $\underline{0.600}$ \\
\hline Three months & 0.454 & $\underline{0.573}$ \\
\hline Breast size doesn't matter & 0.262 & $\underline{0.567}$ \\
\hline Provide all food & 0.348 & $\underline{0.557}$ \\
\hline Pump at work & 0.047 & $\underline{0.525}$ \\
\hline Learn on and off & 0.379 & $\underline{0.392}$ \\
\hline Six months & 0.263 & $\underline{0.368}$ \\
\hline Do most activities & 0.230 & $\underline{0.322}$ \\
\hline${ }^{\star}$ Eat as I please & 0.193 & ---- \\
\hline${ }^{*}$ Take most medications I need & 0.063 & 0.227 \\
\hline *Get information & 0.118 & 0.133 \\
\hline${ }^{*}$ One year & 0.136 & 0.066 \\
\hline Eigenvalues & 9.2 & 1.8 \\
\hline Overall inventory score & 81.0 & 70.0 \\
\hline
\end{tabular}

BPEBI, Breastfeeding Personal Efficacy Beliefs Inventory.

Factor loading $>0.3$; eigenvalue $>1$.

Overall inventory score $=$ the mean score of the individual inventory scores. Note: The item-loading statistic that is underlined indicates the subscale to which each item was assigned.

*Indicates the four items that did not meet the factor-loading criteria of $>0.3$.

exclusively breastfed) in BFC within the Technique and Environment Construct. Multivariate models were created for each construct. Within the Motivation Construct, BFC increased with prior exposure to $\mathrm{BF}(\mathrm{P}=0.006)$ and $\mathrm{EBF}$ $(\mathrm{P}=0.001)$. BFC increased with $\mathrm{EBF}(\mathrm{P}<0.001)$ within the Technique and Environment Construct. 
Table 5. Individual inventory score for each item on the BPEBI

\begin{tabular}{|llll|}
\hline Confidence about the ability to: & Mean & SD & N \\
\hline Improve my baby's health & 86.5 & 19.7 & 238 \\
Get information about breastfeeding & 92.0 & 14.7 & 237 \\
Breastfeed at the mall & 61.9 & 34.2 & 238 \\
Breastfeed with immediate family present & 76.6 & 30.6 & 238 \\
Pump at work and save my milk for baby & 57.3 & 36.1 & 236 \\
Make enough milk no matter breast size & 68.2 & 30.3 & 232 \\
Learn to get baby on and off the breast & 77.6 & 24.8 & 238 \\
Make milk that is safe for my baby & 85.3 & 23.0 & 237 \\
Eat mostly as I please & 54.6 & 31.9 & 233 \\
Get help with the baby while breastfeeding & 75.7 & 27.7 & 232 \\
Expect support from my spouse/partner & 80.6 & 28.0 & 233 \\
Improve my baby's intelligence & 83.7 & 22.3 & 234 \\
Have a pleasant time while breastfeeding & 75.6 & 27.6 & 230 \\
Breastfeed during the nighttime & 87.2 & 20.0 & 236 \\
Save money by breastfeeding & 89.2 & 20.1 & 236 \\
Take most medications I need while & 44.1 & 30.6 & 231 \\
breastfeeding & & & \\
Bond easily with my baby & 88.0 & 18.8 & 235 \\
Ease my return to work by breastfeeding & 60.7 & 29.8 & 229 \\
Do most activities that I want & 61.0 & 33.0 & 235 \\
Provide all my baby's food for several months & 71.5 & 28.9 & 230 \\
Breastfeed right after birth & 87.0 & 21.5 & 235 \\
Breastfeed for three months & 78.9 & 23.9 & 235 \\
Breastfeed for six months & 64.6 & 36.0 & 235 \\
Breastfeed for one year & 70.0 & & \\
\hline Overall confidence inventory score & & & \\
Overall Motivation Construct inventory score & 81.0 & & \\
Overall Technique Construct inventory score & 74.9 & \\
\hline
\end{tabular}

BPEBI, Breastfeeding Personal Efficacy Beliefs Inventory; SD, standard deviation.

Overall confidence inventory score $=$ the mean score of the individual inventory scores.

Construct inventory scores were calculated separately for the two constructs from the items that made up the individual constructs.

Univariate regression was performed to determine the effect of race (black vs. non-black), marital status (married vs. not married), and insurance (Medicaid vs. self-pay) on EBF at hospital discharge. Race and marital status were statistically significant with P-values of 0.003 and 0.004 , respectively, with non-black race and being married positively associated with EBF. Having Medicaid insurance (vs. other insurance types) was negatively associated with $\mathrm{EBF}$, with borderline statistical significance $(\mathrm{P}=0.06)$. Multiple regression revealed that the two main predictors of EBF at discharge were: EBF mothers were less common among those of black race $(\mathrm{P}=0.02)$ and those living within lower SES zip codes of the central city of Milwaukee $(\mathrm{P}=0.01)$.

\section{Discussion}

Based on these findings, using the BPEBI as a tool to assess $\mathrm{BF}$ in this predominantly urban, low SES population suggests that, based on self-reported BFC levels, we would expect these patients to have a substantially high BF initiation rate. Research that has measured the concept of self-efficacy in BF found that participants with high self-efficacy scores breastfed for longer periods and have a higher initiation rate. ${ }^{16}$ This was not the case in this population, with only $56 \%$ of women initiating BF at hospital discharge; there are presumably other factors influencing BF initiation.

Many factors influence infant feeding decisions. These include social influences of the mother's peer group, expectations from society, the partner's attitude about BF, family expectations, mother's level of education about $\mathrm{BF}$ and exposure to $\mathrm{BF} .{ }^{16}$ Specifically, in black women there is disproportionately inadequate support for BF. This lack of support extends from the home, workplace, peers and health care providers. ${ }^{17,18}$ Barriers to $\mathrm{BF}$ in the Women, Infants, and Children (WIC) population have been sorted into five categories: lack of support inside/outside the hospital, returning to work, practical issues, WIC-related issues, and social/cultural barriers. This is a complex population that has many factors influencing BF. Clinical recommendations have included peer-counseling programs, prenatal/postpartum education, in-hospital BF support, and changing the focus of WIC from formula-promoting to BF-promoting, all of which have shown to increase EBF in this population. ${ }^{19}$

Those factors most associated with BFC were black race, age, prior exposure to $\mathrm{BF}$, whether or not this was the first pregnancy, and EBF during the early weeks. The most significant variables associated with the low $\mathrm{BF}$ initiation rates in this population were absence of exposure to $\mathrm{BF}$, failure to breastfeed exclusively immediately postpartum, black race, and living in low SES zip codes of the central city of Milwaukee. ${ }^{15}$ These findings are similar to recent interviews of black women in this area (which comprise $58 \%$ of the same population as this project) about influences on $\mathrm{BF}^{20}$ It is imperative to direct patient education toward increased exposure to $\mathrm{BF}$ in the antenatal period. Improving health behaviors using the behavior change approach based on individual psychology, behaviorism and community-based participatory approach have been successfully utilized in numerous World Health Organization BF programs. Specific strategies include baby-friendly hospital initiatives, in-service staff training, supportive supervision during antepartum care, education using electronic, print and social media (i.e. BF videos in the waiting area, posters of role models supporting 
$\mathrm{BF})$, prenatal lactation classes, centering groups, community advocacy, peer counseling, and networking with mother support groups such as the La Leche League. ${ }^{21}$

Prenatal BF workshops provided to patients have shown increased initiation and duration rates. ${ }^{22} \mathrm{BF}$ classes are often available; however, this service may require a fee that could prevent patients from participating. These workshops are in a lecture format and may not be enticing for young women to participate in due to lack of interaction. An interactive model that promotes exposure and support through peer groups is CenteringPregnancy ${ }^{\odot}$ (Centering Healthcare Institute, Boston, MA). This model has great potential in low SES black populations and has already been shown to increase the number of prenatal care appointments attended, decrease preterm labor and increase $\mathrm{BF}$ initiation rates. ${ }^{23}$ Our medical center has initiated group prenatal care, and we are hopeful that this will impact the initiation rate of $\mathrm{BF}$.

Initiation is the first step; continuation of BF will need continued support for mothers and an environment that promotes successful BF. Multiple interventions have been previously studied, with validated surveys available to identify possible issues in women who have chosen to breastfeed. Britton et al., in a systematic review and meta-analysis of 34 randomized trials, showed a significant beneficial effect of lay and professional BF support, particularly on $\mathrm{EBF}^{24}$

Lactation consultants have been shown to increase BF initiation rates at hospital discharge through promotion and education of the mother, spouses/partners and immediate family members. Past research by Oza-Frank et al. demonstrated that a mother receiving the services of both a lactation consultant and peer counselor was 34\% more likely to provide any breast milk to their infant in the NICU, compared to only lactation consultants $(11 \%)$ or only peer counselors (14\%). ${ }^{25}$ Our institution has lactation consultants available 7 days a week for all mothers; an additional service to add would be a peer counselor.

The contradictory view of the WIC program as supporting $\mathrm{BF}$ on one hand but also promoting formula on the other delivers mixed messages to the population that it serves. ${ }^{18}$ WIC provides free supplemental formula to mothers and does not endorse EBF as an important health goal. Participation in the WIC program during the first trimester is associated with reduced duration of $\mathrm{BF}$, participation during any trimester is related to increased formula feeding, and participation at 2-4 months is associated with increased risk of BF discontinuation by $50 \%$. The more formula that is consumed creates additional funding, which enables the WIC program to reach more families. However, if the program is reaching families with the wrong or confusing messages, broader coverage might not be beneficial. In the New York City WIC office, a shift has been made from WIC being the "formula people" to the "BF people;" removing all formula from its office has helped to promote BF within the population. ${ }^{18}$

In regards to continuous support after delivery, it has been noted that mothers who give birth at Baby-Friendlyaccredited hospitals are more likely to initiate EBF and more likely to sustain it at 6 months and 1 year of age. ${ }^{26}$ To attain Baby-Friendly status, adherence to the Ten Steps to Successful Breastfeeding is advised as well as using the 4-D pathway to designation. ${ }^{27}$ Using this method creates an environment that is supportive of best practices in maternity care and of optimal infant feeding. This, along with addition of a peer counselor and steps to recreate WIC as a BF-promoting rather than formula-promoting program, would be new initiatives for our institution and would help support the community in promoting BF. Also important to our institution would be to offer vouchers to women who are unable to pay for BF information classes.

In addition to the aforementioned possible explanations, an alternative explanation for some of the mismatch between calculated $\mathrm{BFC}$ and $\mathrm{BF}$ initiation rates may be the performance of the BPEBI instrument in this patient population, particularly given that the two identified factors explained less than $50 \%$ of the variance. This may relate to the fact that the BPEBI was validated in a different racial and socioeconomic demographic than the project population. Further investigation could attempt to construct questions that would more accurately query those issues which encourage or discourage BF initiation rates in this setting.

Limitations of this project include its moderate sample size from a single institution, the anonymity of the survey, which did not allow correlation of confidence score with actual $\mathrm{BF}$ initiation rate, that the timing of prior $\mathrm{BF}$ exposure was unknown, and the fact that the BPEBI has not been specifically validated in the project population. The validity of the BPEBI in this population will need more exploration to determine if this tool can be used in the future to reliably predict BF initiation rates. Strengths of this project include high survey response rate (perhaps aided by anonymity of the survey) and the use of a previously validated survey instrument in an unexplored urban population. 


\section{Conclusions}

Women in this urban population need more exposure to breastfeeding during the antenatal period and continued support after initiation to increase the rate of $\mathrm{BF}$ and reach the goals of Health People 2020. Despite the complexity of individuals in this population, this survey demonstrated they have the self-reported confidence to breastfeed. The low BF rates among this population may be the result of lack of support from health care providers or programs inside/outside the hospital as well as sociocultural and economic barriers that emerge at the time of BF decisions. Racial and demographic barriers cannot be changed, but interventions can be designed to address them in a culturally sensitive manner. With this information we can now direct patient-centered tools (peer counselors, BF class vouchers, decreased formula use in the hospital, etc.) for improvement in BF at our institution, as can similar urban facilities. Future assessment of success of any proposed interventions can be measured by $\mathrm{BF}$ initiation and continuation rates.

\section{Acknowledgments}

We would like to thank Ann Pollard Cleveland, EdD, MSN, RN, for allowing us to use the BPEBI, without this instrument this project would not have been possible. Additionally, we thank Kara Ackerman for her hard work and diligence in obtaining complete surveys.

\section{Conflicts of Interest}

None

\section{References}

1. Section on Breastfeeding, Johnston M, Landers S, Noble L, Szucs K, Viehmann L. Breastfeeding and the use of human milk. Pediatrics. 2012;129:3:e827-41.

2. World Health Organization. Report of the Expert Consultation on the Optimal Duration of Exclusive Breastfeeding. Geneva, Switzerland: World Health Organization, 2001;1-6.

3. Committee on Health Care for Underserved Women, American College of Obstetricians and Gynecologists. ACOG Committee Opinion No. 361: Breastfeeding: maternal and infant aspects. Obstet Gynecol. 2007;109:479-80.

4. Gartner LM, Morton J, Lawrence RA, et al. Breastfeeding and the use of human milk. Pediatrics. 2005;115:496-506.

5. Boland M. Exclusive breastfeeding should continue to six months. Paediatr Child Health. 2005;10:148.

6. Royal College of Paediatrics and Child Health. England, Whales, and Scotland: The College 2007-2010. Police Statement-Child Health. Available at: www.rcpch.ac.uk/child-health/ standards-care/positionstatements/position-statements. Accessed Dec. 26, 2012.

7. Ip S, Chung M, Raman G, et al. Breastfeeding and maternal and infant health outcomes in developed countries. Evid Rep Technol Assess (Full Rep). 2007;(153):1-186.

8. Healthy People 2020. Maternal, infant, and child health. Available at: http://www.healthypeople.gov/2020/topicsobjectives2020/ objectiveslist.aspx?topicId=26. Accessed Aug. 28, 2013.

9. Center for Disease Control and Prevention. Breastfeeding report card - United States, 2012. Available at: www.cdc.gov/breastfeeding/ pdf/2012BreastfeedingReportCard.pdf. Accessed Dec. 26, 2012.
10. Center for Disease Control and Prevention. Pediatric nutrition surveillance system (PedNSS)-WIC data. Available at: www.dhs. wisconsin.gov/wic/WICPRO/data/PedNSS/10metro.pdf. Accessed Dec. 26, 2012.

11. Bandura A. Self-efficacy: toward a unifying theory of behavioral change. Psychol Rev. 1977;84:191-215.

12. Bandura A. Self-Efficacy: The Exercise of Control. New York: W.H. Freeman and Company, 1997.

13. Cleveland AP, McCrone S. Development of the Breastfeeding Personal Efficacy Beliefs Inventory: a measure of women's confidence about breastfeeding. J Nurs Meas. 2005;13:115-27.

14. Grimm LG, Yarnold PR. Reading and Understanding Multivariate Statistics. Washington, D.C.: American Psychological Association, 2004.

15. Chen HY, Baumgardner DJ, Frazer DA, Kessler CL, Swain GR, Cisler RA. Milwaukee Health Report 2012: Health Disparities in Milwaukee by Socioeconomic Status. Milwaukee: Center for Urban Population Health, 2012.

16. Wells KJ, Thompson NJ, Kloeblen-Tarver AS. Development and psychometric testing of the prenatal breast-feeding self-efficacy scale. Am J Health Behav. 2006;30:177-87.

17. Street DJ, Lewallen L. The influence of culture on breast-feeding decisions by African American and white women. J Perinat Neonatal Nurs. 2013:27:43-51.

18. Kelka TR, Jensen E, McLaurin S, et al. Community based participatory research of breastfeeding disparities in African American women. Infant Child Adolesc Nutr. 2011;3:233-9.

19. Hedberg IC. Barriers to breastfeeding in the WIC population. MCN Am J Matern Child Nurs. 2013;38:244-9.

20. Robinson KM, VandeVusse L. African American women's infant feeding choices: prenatal breast-feeding self-efficacy and narratives from a black feminist perspective. J Perinat Neonat Nurs. 2011:25:320-8.

21. Morrow A. Community Based Strategies for Breastfeeding Promotion and Support in Developing Countries. Geneva, Switzerland: World Health Organization. Available at: http://whqlibdoc.who.int/ publications/2003/9241591218.pdf. Accessed Dec. 26, 2012.

22. Noel-Weiss J, Rupp A, Cragg B, Bassett V, Woodend AK. Randomized controlled trial to determine effects of prenatal breastfeeding workshop on maternal breastfeeding self-efficacy and breastfeeding duration. J Obstet Gynecol Neonatal Nurs. 2006;35:616-24.

23. Ickovics JR, Kershaw TS, Westdahl C, et al. Group prenatal care and perinatal outcomes: a randomized controlled trial. Obstet Gynecol. 2007;110:330-9.

24. Britton C, McCormick FM, Renfrew MJ, Wade A, King SE. Support for breastfeeding mothers. Cochrane Database Syst Rev. 2007;(1):CD001141.

25. Oza-Frank R, Bhatia A, Smith C. Combined peer counselor and lactation consultant support increases breastfeeding in the NICU. Breastfeed Med. 2013;8:509-10.

26. Merewood A, Mehta SD, Chamberlain LB, Philipp BL, Bauchner $\mathrm{H}$. Breastfeeding rates in US Baby-Friendly hospitals: results of a national survey. Pediatrics. 2005;116:628-34.

27. Baby-Friendly USA. Guidelines and Criteria. Available at: http://www.babyfriendlyusa.org. Accessed Dec. 26, 2012.

(C) 2014 Aurora Health Care, Inc. 